\title{
Avanços e Recuos do Mercosul: Um Balanço Recente dos Seus Objetivos e Resultados
}

\author{
João Batista Pamplona (*) \\ Juliana Fernanda Alves da Fonseca ${ }^{(*)}$
}

Resumo: Este artigo objetiva avaliar em que medida os objetivos estabelecidos na constituição e evolução do Mercosul foram cumpridos, para dessa forma identificar ou não a existência de uma crise no esquema de integração regional. Quatro fases são identificadas na trajetória do Mercosul. A primeira (1991 a 1994) foi um período de avanços e consolidação do Bloco. A segunda fase (1995 a 1998) foi marcada por uma agenda mais complexa e conflituosa, mas a implementação da Tarifa Externa Comum representou avanço na integração comercial. Na terceira (1999 a 2002), deflagrou-se na região uma conjuntura de recessão e incerteza, com o comércio intrabloco sofrendo forte redução. Foi uma fase de crise para a integração. A quarta fase (2003 a 2007) foi caracterizada por forte crescimento do comércio intrabloco e a existência de conflitos que refletiram muito mais a intensificação do processo de integração do que sua crise.

Palavras-chave: Mercosul, Objetivos e Fases do Mercosul, Integração Econômica, Tarifa Externa Comum, Comércio Intrabloco.

\begin{abstract}
This article aims to evaluate in which ways the established objectives in the constitution and evolution of the Mercosur have been fulfilled, so that it would be possible to identify or not the existence of a crisis in the project of regional integration. Four stages are identified in the trajectory of the Mercosur. The first one $(1991$ - 1994) was a period of progress and consolidation of the block. The second stage $(1995-1998)$ was stressed by a more complex and unsettled agenda but the implementation of the TEC represented progress in the commercial integration. During the third one $(1999-2002)$ an uncertainty and recession conjuncture exploded in the region. The intrabloc trade suffered strong reduction. It was a stage of crisis for the integration. The fourth stage (2003 - 2005) was characterized by a strong growth of the intrabloc trade and the existence of conflicts which reflected a lot more the intensification of the integration process than its crisis.
\end{abstract}

Keywords: Mercosur, Objectives and Stages of the Mercosur, Economic Integration, Common External Tariff.

(*) Professor doutor do Departamento de Economia da PUC-SP. E-mail: pamplona@pucsp.br.

(**) Economista pela PUC-SP. E-mail: juli.fonseca@uol.com.br . Recebido em: 2.7.08 e aceito em: 4.9.08 


\section{INTRODUÇÃo}

O Mercado Comum do Sul (Mercosul) foi constituído por meio da assinatura do Tratado de Assunção, que em março de 2008 completou 17 anos de existência. No decorrer deste período, o Mercosul passou por momentos contraditórios: fases em que as expectativas com relação ao seu futuro foram muito favoráveis e momentos em que estas foram consideravelmente pessimistas.

O Mercosul se apresenta como uma grande oportunidade para os países da América do Sul expandirem seus mercados, ampliando economias de escala; aumentarem a mobilidade dos seus fatores de produção, permitindo uma melhor utilização de recursos escassos; intensificarem a concorrência dentro da área integrada, obtendo ganhos de eficiência ${ }^{(1)}$; ampliarem suas conexões econômicas e políticas, gerando maior poder de negociação extrabloco e maior estabilidade intrabloco.

Um aspecto importante do processo de aproximação dos países sul-americanos é que este se deu em conjunto com a redemocratização de suas sociedades, o que foi primordial para possibilitar a formação e a manutenção do bloco regional. Ademais, fatos como a associação da Colômbia, do Equador, do Peru, do Chile e da Bolívia ao bloco e a adesão da Venezuela em 2006 como país-membro do Mercosul, reforçam a afirmação de muitos que consideram o esquema de integração da região irreversível.

No entanto, o contexto atual, caracterizado entre outros pelas negociações entre o Uruguai e os Estados Unidos da América para um acordo de preferências comerciais bilaterais, pelo conflito entre o Uruguai e a Argentina com relação à construção de duas plantas de celulose na fronteira destes países e pela decisão do governo boliviano que nacionalizou os ativos da empresa Petróleo Brasileiro S/A., revela a importância de uma avaliação do processo de integração da região sul-americana, pois estes fatos trazem à tona a seguinte questão: a conjuntura atual é um indicativo de que o processo de integração da região está em crise? E, consequentemente, no caso da resposta ser positiva, qual é a dimensão desta crise?

O objetivo central deste artigo é avaliar em que medida os objetivos estabelecidos no Tratado de Assunção e no decorrer do processo de constituição do bloco estão sendo cumpridos, para assim diagnosticar a existência ou não de uma crise no esquema de integração da região. Os objetivos secundários correspondem à revisão do processo de formação do Mercosul e à atualização dos objetivos e instrumentos do bloco, tendo em vista as modificações ocorridas no período de 1991 a 2007.

O procedimento de pesquisa consiste da pesquisa bibliográfica que engloba a seleção, a análise, o resumo, a complementação e a confrontação de referências bibliográficas amplas e atualizadas, das quais são extraídas interpretações de autores, informações de documentos e estatísticas sobre o comércio internacional na região.

(1) Os efeitos dinâmicos do processo de integração econômica, para o Mercosul e outros casos, são detalhadamente apresentados em Salvatore (2000), Appleyard e Field Jr. (2001), Constâncio (2005). 
Com o intuito de alcançar o objetivo proposto, este artigo está divido em três partes, além da introdução e conclusão. O primeiro tópico trata dos fatos que antecederam à constituição do bloco regional e os objetivos estabelecidos no Tratado de Assunção. O segundo apresenta a evolução dos objetivos do Mercosul em sua primeira década (1991 a 1998) e os acontecimentos transcorridos no período, que permitem avaliar se os principais objetivos do bloco foram cumpridos ou não. O terceiro tópico complementa a análise e, neste sentido, aborda a evolução dos objetivos do Mercosul no período recente (1999 a 2007) e os fatos do período que refletem os sucessos e insucessos do bloco no alcance dos seus objetivos.

\section{Origem do Mercosul e os objetivos iniciais do Tratado de Assunção}

Brasil e Argentina inauguraram o processo de integração econômica da região, em 1986, por meio da assinatura da "Ata para Integração Brasil-Argentina", na qual foi instituído o Programa de Integração e Cooperação Econômica (PICE). Após obterem resultados positivos e promissores, os dois países estabeleceram, em 1988, o Tratado de Integração, Cooperação e Desenvolvimento, que tinha o intuito maior de promover um espaço econômico comum. (ALMEIDA, 1998, p. 45-46)

E, em 26 de março de 1991, após outros acordos e uma considerável repercussão regional, os presidentes da Argentina, do Brasil, do Paraguai e do Uruguai constituíram, por meio da assinatura do Tratado de Assunção, o Mercado Comum do Sul, o qual passou a conduzir as relações econômico-comerciais dos quatro países. (ALMEIDA, 1998, p. 46-47)

O propósito inicial do Tratado de Assunção era estabelecer o Mercado Comum do Sul até 31 de dezembro de 1994, o que implicava na:

- eliminação dos direitos alfandegários e das restrições não tarifárias à circulação das mercadorias, com o intuito de promover a livre-circulação dos bens, serviços e fatores produtivos entre os países-membros;

- instituição de uma Tarifa Externa Comum (TEC), adoção de uma política comercial comum em relação ao resto do mundo e também coordenação de posições em foros econômico-comerciais regionais e internacionais;

- coordenação das políticas macroeconômicas e setoriais dos países-membros, para, assim, garantir adequadas condições de concorrência;

- harmonização das legislações, nas áreas pertinentes, para, deste modo, fortalecer o processo de integração.

A fim de facilitar a constituição do Mercosul e, neste sentido, alcançar seus objetivos, o Tratado de Assunção instituiu:

- um Regime Geral de Origem, um Sistema de Solução de Controvérsias e Cláusulas de Salvaguarda; 
- um programa de liberalização comercial progressivo, com o intuito de se obter tarifa zero para todo o comércio intrabloco, até 31 de dezembro de 1994;

- a coordenação das políticas macroeconômicas da região;

- listas de exceções aos produtos sensíveis da economia de cada país ao programa de liberalização comercial;

- a adoção de acordos setoriais;

- uma TEC com o objetivo de aumentar a competitividade dos países-membros por meio de políticas comerciais e investimentos conjuntos.

Ademais, no lugar de uma institucionalidade supranacional, os quatro países decidiram adotar mecanismos de caráter intergovernamental.

\section{O desenvolvimento inicial do Mercosul: a primeira década (1991 a 1998)}

\section{A EVOLUÇÃO DOS OBJETIVOS NA PRIMEIRA DÉCADA (1991 A 1998)}

Almeida (1998, p. 88-92) e Muarrek (2004, p. 26-32, 169-171) revelam que após a assinatura do Tratado de Assunção em 1991, as negociações evoluíram e, neste sentido, os países-membros modificaram parcialmente o tratado e estabeleceram novos desafios.

Em 14 de outubro de 1992, os países-membros aprovaram o Cronograma de Las Leñas, com o intuito de estabelecer prazos para a realização dos compromissos firmados no Tratado de Assunção. Neste sentido, o cronograma definiu as prioridades e os instrumentos da integração com base na avaliação das assimetrias existentes entre os países-membros.

Em 17 de dezembro de 1994, foi aprovado o Protocolo de Ouro Preto, relativo aos aspectos institucionais do Mercosul, o qual modificou parcialmente o Tratado de Assunção e conferiu personalidade jurídica internacional ao bloco.

No mesmo mês (dezembro de 1994), os países-membros acordaram sobre a Tarifa Externa Comum, a qual visava equalizar as alíquotas destes com relação a terceiros. Neste sentido, os quatro países decidiram estabelecer a TEC em janeiro de 1995. No entanto, devido a diferenças de estrutura e de graus de desenvolvimento industrial entre o Brasil e os demais sócios, os países partícipes defiram, para um período denominado de "fase de convergência”, ou seja, até 2001-2006, listas nacionais de exclusão à TEC, as quais eram compostas, por exemplo, de bens de capital e informática.

Ademais, neste ano (1994), os sócios fixaram, dentro do Programa de Liberalização Automática, por conta de um conjunto de produtos sensíveis, um "novo" calendário automático de eliminação de tarifas, com prazo, para adequação, até, no máximo, janeiro de 2000. (BOUZAS, 2001, p. 3)

Em 24 de julho de 1998, durante a XIV Reunião de Cúpula do Mercosul, os países-membros e os países-membros associados (Bolívia e Chile) assinaram o Protocolo de 
Ushuaia, o qual estabeleceu que, necessariamente, para participar do bloco, os países possuam regimes democráticos.

\section{O desenvolvimento inicial do Mercosul: um panorama dos resultados da PRIMEIRA DÉCADA}

Segundo Bouzas (2001, p. 1-2), a trajetória do Mercosul, durante a sua primeira década de existência, pode ser divida em três períodos distintos ${ }^{(2)}$ : o "período de transição", de 1991 a 1994; a "era dos mercados", de 1995 a 1998, e os "tempos de turbulência", que compreendem o período de 1998 em diante.

No presente artigo estes períodos serão caracterizados por meio dos acontecimentos que refletem o alcance, ou não, dos objetivos estabelecidos no Tratado de Assunção e no decorrer do processo mais amplo de integração. Neste sentido, este tópico analisará somente as duas primeiras fases do esquema de periodização da integração da região proposto por Bouzas (2001), ou seja, o período de 1991 a 1994 e o de 1995 a 1998. O tópico seguinte apresentará o período subsequente (1999 em diante), com o intuito de seguir com a avaliação do alcance dos objetivos do bloco.

\section{A PRIMEIRA FASE: 1991 A 1994}

Segundo Bouzas (2001, p. 7), durante este período, denominado no Tratado de Assunção de "período de transição", o Mercosul teve seu desempenho influenciado por uma conjuntura favorável, com a presença de políticas nacionais convergentes, a negociação de uma agenda voltada para uma "integração superficial" e um ambiente externo favorável. Tal conjunto de fatores impulsionou o progresso do esquema de integração regional, particularmente nos seus estágios iniciais.

Neste sentido, a execução do Programa de Liberalização Automática, que promoveu cortes lineares e automáticos nas tarifas aduaneiras dos quatro países, gerou um aumento significativo da interdependência comercial na região, visto que o fluxo de comércio intrarregional cresceu substancialmente (Gráfico 1). O comércio intrabloco passou de US\$ 10.201,1 milhões em 1991 para US\$23.712,9 milhões em 1994, ou seja, aumentou 132\%. No mesmo período, o comércio extrabloco (extrazona) cresceu bastante menos (apenas 42\%). O comércio intrabloco do Mercosul no período 1991-1994 aumentou a uma taxa média ${ }^{(3)}$ expressiva de mais de $30 \%$ ao ano. Já o comércio extrabloco cresceu à taxa média de $10 \%$ ao ano. Um outro dado que demonstra o aumento da integração comercial no período é a participação do comércio intrabloco no comércio total da região, que passou de $13 \%$ para algo como $20 \%$ (Tabela 1). Em apenas quatro anos, o bloco fez mais progresso na integração e liberalização do comércio na região do que nas três décadas anteriores.

(2) Para detalhes de como o autor identificou estes três períodos ver Bouzas (2001, p. 1-2).

(3) As taxas médias de crescimento referidas neste artigo são taxas médias aritméticas. 
Tabela 1 - Desempenho comercial do Mercosul, no período 1991 a 1998 (em US\$ Milhões)

\begin{tabular}{|c|c|c|c|c|c|c|c|c|}
\hline & 1991 & Var. \% & 1992 & Var. \% & 1993 & Var. \% & 1994 & Var. \% \\
\hline $\begin{array}{l}\text { Comércio } \\
\text { intrazona (A) }\end{array}$ & 10.201 & 24 & 14.497 & 42 & 19.143 & 32 & 23.712 & 24 \\
\hline $\begin{array}{l}\text { Comércio } \\
\text { extrazona (B) }\end{array}$ & 68.038 & 4 & 74.846 & 10 & 80.743 & 8 & 96.486 & 19 \\
\hline $\begin{array}{l}\text { Comércio } \\
\text { total }(\mathrm{C})\end{array}$ & 78.239 & 6 & 89.344 & 14 & 99.886 & 12 & 120.197 & 20 \\
\hline \multirow[t]{2}{*}{$(\mathrm{A} / \mathrm{C})$} & $13,0 \%$ & & $16,2 \%$ & & $19,2 \%$ & & $19,7 \%$ & \\
\hline & 1995 & Var. \% & 1996 & Var. \% & 1997 & Var. \% & 1998 & Var. \% \\
\hline $\begin{array}{l}\text { Comércio } \\
\text { intrazona (A) }\end{array}$ & 28.438 & 20 & 34.226 & 20 & 40.981 & 20 & 40.814 & 0 \\
\hline $\begin{array}{l}\text { Comércio } \\
\text { extrazona (B) }\end{array}$ & 117.806 & 22 & 124.066 & 5 & 139.138 & 12 & 135.829 & -2 \\
\hline $\begin{array}{l}\text { Comércio } \\
\text { total }(\mathrm{C})\end{array}$ & 146.245 & 22 & 158.292 & 8 & 180.119 & 14 & 176.644 & -2 \\
\hline$(\mathrm{A} / \mathrm{C})$ & $19,4 \%$ & & $21,6 \%$ & & $22,8 \%$ & & $23,1 \%$ & \\
\hline
\end{tabular}

FONTE: Elaboração própria com base em CEI (2008), citando INDEC, SECEX, Secretaria Administrativa do Mercosul, Banco Central do Uruguai e Banco Central do Paraguai.

Gráfico 1 - Intercâmbio comercial do Mercosul, no período 1991 a $1998(1991$ = base 100$)$

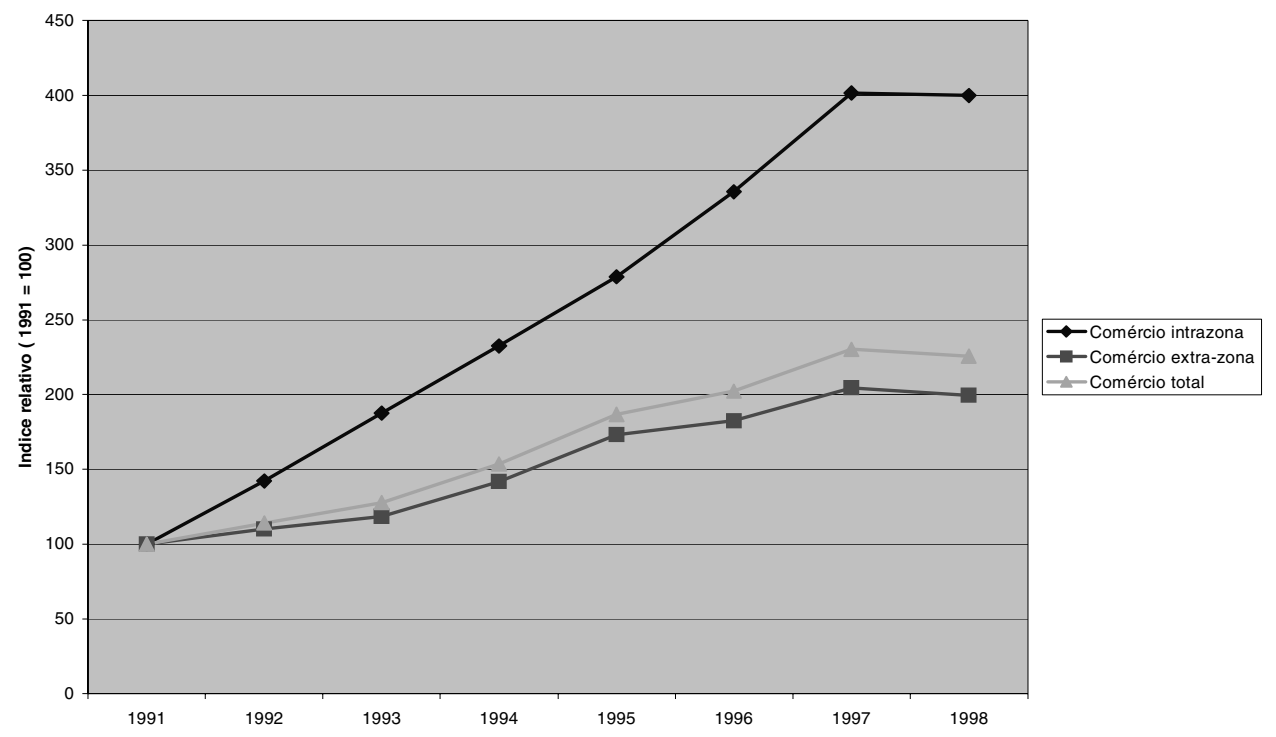

FONTE: Elaboração própria com base em CEI (2008), citando INDEC, SECEX, Secretaria Administrativa do Mercosul, Banco Central do Uruguai e Banco Central do Paraguai. 
No final de 1994, a maior parte do comércio intrarregional já estava submetida à tarifa zero, exceto um conjunto de produtos sensíveis que seguiram o novo calendário automático de eliminação de tarifas, com prazo-limite para adequação até janeiro de 2000. Dois setores especiais (açúcar e veículos automotores) ficaram, transitoriamente, fora do acordo de livre comércio. Sendo assim, o Mercosul conseguiu na sua primeira fase, conforme previsto no Tratado de Assunção, atingir em boa medida o objetivo relacionado com a liberalização do comércio intrarregional. (BOUZAS, 2000, p. 430; BOUZAS, 2001, p. 7)

No entanto, no âmbito das barreiras não tarifárias, os avanços foram bem mais modestos, visto que os países-membros concordaram em excluir apenas 13 das barreiras não tarifárias (relacionadas, principalmente, com as proibições de importação e as restrições quantitativas).

Machado (2000, p. 73) argumenta que a agenda de Las Leñas priorizou "o tratamento dos temas relativos ao comércio exterior em detrimento dos demais". Neste sentido, na esfera da coordenação macroeconômica, o Mercosul não obteve avanços, visto que nenhum mecanismo foi definido nesta área.

No fim de 1994, os quatro países ainda acordavam sobre a TEC e o código aduaneiro comum. Portanto, ao final desta fase de transição, o Mercosul ainda não tinha cumprido os critérios para a formação de um mercado comum. Ou seja, os países-membros não atingiram o principal objetivo estabelecido no Tratado de Assunção, instituir o Mercado Comum do Sul até 31 de dezembro de 1994.

Contudo, devemos ressaltar novamente que os quatro países avançaram significativamente no campo da integração e liberalização do comércio intrarregional. (PEREIRA, 1998, p. 11) Neste sentido, apesar de não ter sido alcançado o maior objetivo do Tratado de Assunção (o mercado comum) devido, segundo Averbug (1998, p. 2), "à complexidade que envolve a integração de países com características econômicas, políticas, sociais e culturais distintas", o balanço do período apresenta, no geral, um saldo positivo. Pois, ao final do período, a maior parte dos produtos comercializados entre os países-membros circulava com isenção de impostos e o comércio intrarregional tinha aumentado expressivamente.

\section{A SEgunda FASE: 1995 A 1998}

A implementação da Tarifa Externa Comum em janeiro de 1995 marca o fim do período de transição e, consequentemente, o início de uma nova etapa, transcorrida entre 1995 e 1998. Com isto, os quatro países formaram uma "união aduaneira imperfeita"(4), visto que, junto com a TEC, os sócios definiram, para um período denominado de "fase de convergência", ou seja, até 2001-2006, listas nacionais de exclusão à TEC, que incluíam, por exemplo, os bens de capital e os produtos de informática do mercado regional.

(4) Na união aduaneira, além da eliminação das barreiras comercias entre os países membros, há uma harmonização das políticas comerciais desses com relação a terceiros. Para isso, institui-se a Tarifa Externa Comum (TEC), que equaliza as alíquotas que afetam a relação citada. BALASSA, 1972, p. 13; SALVATORE, 2000, p. 175. O Mercosul é um exemplo de união aduaneira, no entanto, devido às inúmeras exceções à TEC, que os países membros mantêm até os dias de hoje, é possível classificar o bloco como uma "união aduaneira imperfeita". 
A fase de 1995 a 1998 foi marcada por contrastes. Ao mesmo tempo em que a interdependência comercial aumentou, ocorreu também o crescimento da paralisia regulatória, pois, segundo Bouzas (2001, p. 4), no decorrer deste período, a imagem prevalecente era a de que o Mercosul era tão bem-sucedido que poderia seguir impulsionado somente pelos interesses do setor privado, o que relegou a agenda interna a segundo plano.

O índice de regionalização do comércio externo ${ }^{(5)}$, que tinha crescido cerca de $50 \%$ entre 1991 e 1994, continuou crescendo no período de 1995 a 1998 (19\%). Ele aumentou menos, mas de uma forma expressiva. O Gráfico 1 e a Tabela 1 demonstram a trajetória ascendente do comércio intrazona, que se expandiu também no período 1995-1998 a uma taxa média superior àquela verificada no comércio extrazona ${ }^{(6)}$. Do mesmo modo, junto com os fluxos de comércio, os fluxos de investimentos se intensificaram, visto que foram estimulados pelo crescente dinamismo das relações econômicas na região.

Por outro lado, segundo Bouzas (2001), na esfera das barreiras não tarifárias e das políticas comerciais quase nenhum progresso foi alcançado, já que as barreiras não tarifárias permaneceram intocadas. A TEC foi implementada parcialmente, exceções temporárias foram autorizadas e o código aduaneiro comum revelou-se inaplicável. Segundo Machado (2000, p. 81), isto foi consequência do baixo grau de harmonização das políticas no Mercosul.

Contudo, os dois maiores sócios do bloco (Brasil e Argentina) apresentaram políticas macroeconômicas convergentes, visto que a implantação do Plano Real, em 1994, pelo Brasil, aproximou as políticas de estabilização e o tipo de câmbio dos dois países. Neste sentido, o Plano Real propiciou uma forte expansão da economia brasileira e, assim, toda a região compreendida pelo Mercosul foi beneficiada. Entretanto, a partir de 1998, a economia internacional tornou-se desfavorável e isto criou um ambiente externo pouco propício para o avanço do processo de integração. (BOUZAS, 2000, p. 432)

Em 1998, a crise internacional e os problemas macroeconômicos por ela desencadeados, afetaram o comércio externo da região. Nesse ano, o comércio total sofre redução de $2 \%$ e o comércio intrabloco fica estagnado. Em 1998, a interdependência comercial começou a diminuir, pois, diante da vulnerabilidade externa após as crises asiática e russa, os países-membros, principalmente o Brasil, preferiram manter certos recursos de flexibilidade ao invés de adotar compromissos rígidos com relação ao processo de integração, visto que a adoção destes compromissos poderia, por exemplo, reduzir a capacidade de reação discricional dos respectivos países diante do conturbado contexto macroeconômico internacional. Portanto, os incrementos registrados no comércio intrarregional durante os anos 90, os quais elevaram substancialmente a interdependência, não foram suficientes para incentivar uma maior coordenação dentro do bloco e para garantir que a interdependência seguisse crescendo depois de 1998.

Após o período de transição, correspondente à primeira fase (1991 a 1994), iniciou-se uma fase (1995 a 1998) com muitos impasses e temas pendentes, visto que a agenda de

(5) O índice de regionalização do comércio externo é definido como a participação do comércio intrarregional no comércio total.

(6) O comércio intrazona cresceu no período a uma taxa média anual aritmética de cerca de $15 \%$ e o comércio extrazona aumentou a uma taxa de $10,5 \%$. 
negociação se tornou mais complexa e conflitiva. Contudo, o aumento da interdependência comercial, registrado até meados de 1998, e a implementação da TEC, mesmo que com uma série de exceções, foram importantes avanços do segundo período.

\section{Desenvolvimento recente do Mercosul: A Segunda década (1999 a 2007)}

\section{A EVOLUÇÃO DOS OBJETIVOS NA SEGUNDA DÉCADA (1999 A 20O7)}

No período recente, ou seja, de 1999 a 2007, os objetivos do bloco foram, assim como no período anterior (1991 a 1998), revistos e atualizados pelos países-membros.

O Portal Oficial do Mercosul (2007) revela que, em abril de 2000, os quatro sócios adotaram a agenda de relançamento do Mercosul, a qual estabeleceu novas regras e disciplinas relativas ao processo de integração da região ${ }^{(7)}$.

Em 15 de dezembro de 2000, a Argentina, o Brasil, o Paraguai, o Uruguai, a Bolívia e o Chile, assinaram, de acordo com Brasil (2007), a Declaração Presidencial sobre Convergência Macroeconômica, que aprovou as metas e os mecanismos de convergência macroeconômica do Mercosul. As metas, segundo Almeida (2002, p. 45), foram definidas do seguinte modo: 1) a partir de 2002, variação da dívida fiscal líquida do setor público de no máximo $3 \%$ do PIB; 2) a partir de 2010, dívida líquida do setor público limitado a 40\% do PIB; 3) a partir de 2006, um "núcleo inflacionário" não superior a $3 \%$ ao ano. Ademais, foram estabelecidos procedimentos para a correção de desvios em relação às metas.

Em 18 de fevereiro de 2002, com o propósito de consolidar a segurança jurídica do bloco, os países-membros assinaram o Protocolo de Olivos para a solução de controvérsias no Mercosul e, assim, conferiu-se um aperfeiçoamento do sistema de solução de controvérsias do bloco. (PORTAL OFICIAL DO MERCOSUL, 2002)

Segundo o Ministério das Relações Exteriores (2007), em 6 de outubro de 2003, os quatro sócios aprovaram o Programa de Trabalho 2004-2006, o qual, a fim de desenvolver os objetivos e as linhas de ação do esquema de integração, estabeleceu os seguintes programas: 1) Programa político, social e cultural; 2) Programa da união aduaneira; 3) Programa de bases para o mercado comum; 4) Programa da nova integração.

Neste contexto, em 2005, os países-membros estabeleceram o Fundo para a Convergência Estrutural do Mercosul (FOCEM) e, em substituição à Comissão Parlamentar Conjunta, o Parlamento do Mercosul. Ambos constituídos com o intuito de fortalecer e aprofundar a estrutura institucional do bloco.

Em 9 de dezembro de 2007, os presidentes da Argentina, do Brasil, da Bolívia, do Equador, do Paraguai, do Uruguai e da Venezuela assinaram, no âmbito da União de Nações Sul-Americanas (UNASUL), a ata de fundação do Banco do Sul, cujo objetivo é

(7) A agenda de relançamento do Mercosul priorizou o tratamento das seguintes áreas: acesso ao mercado; agilização dos trâmites em fronteiras; incentivos aos investimentos, à produção e à exportação; TEC; defesa comercial e defesa da concorrência; solução de controvérsias; incorporação da normativa Mercosul; fortalecimento institucional do bloco; relações externas; financiamento para o desenvolvimento; avaliação das listas de trabalho dos subgrupos, comitês e reuniões especializadas. 
João Batista Pamplona/Juliana Fernanda Alves da Fonseca — Cadernos PROLAM/USP (Ano 7 - Vol. 2 - 2008) p. 7-23

financiar projetos de desenvolvimento na América do Sul. A fundação do Banco do Sul procura também fortalecer a estrutura institucional do esquema de integração da região.

\section{O desenvolvimento atual do Mercosul: um panorama dos resultados da SEGUNDA DÉCADA}

A partir de 1999, ocorreram fatos que produziram duas inflexões na trajetória do Mercosul. A primeira ocorreu em 1999, propiciada, principalmente, por um ambiente externo desfavorável. A segunda, em 2003, foi devido a uma melhora da economia internacional, além da eleição de Luiz Inácio Lula da Silva para presidente do Brasil, em outubro de 2002, e as vitórias de governos de centro-esquerda na Argentina e no Uruguai, os quais retomaram a agenda interna do bloco. Portanto, para que seja possível melhor analisar o período de 1999 a 2007, vamos dividi-lo em duas fases: de 1999 a 2002 e de 2003 a 2007.

Assim, com o intuito de complementarmos nossa análise, seguem os acontecimentos, transcorridos na terceira e quarta fases do Mercosul, que refletem os sucessos e insucessos dos objetivos do bloco no período recente.

\section{A terceira faSe: 1999 a 2002}

Segundo Sica (2006, p. 7), o período compreendido entre 1999 e 2002 foi fortemente marcado por "volatilidades extremas de las economías, fuertes crisis coyunturales, importante caída de los niveles de actividad y comercio, y ahondamientos de las asimetrías subyacentes".

Para INTAL (2000, p. 12), a desvalorização do real, em janeiro de 1999, e o estabelecimento na região de um cenário comum de incerteza e recessão econômica - os quais decorreram da crise financeira que se instalou nos países asiáticos em meados de 1997 e que acometeu os países do Cone Sul na primeira metade de 1998 - intensificaram a tendência de retração comercial iniciada em meados de 1998. Neste sentido, constatamos que durante o ano de 1999 o comércio total do mercado regional decresceu substancialmente. Em 1999, na comparação com o ano anterior, o intercâmbio entre os países do Mercosul diminuiu $25 \%$ e o comércio total com o resto do mundo retraiu, aproximadamente, $13 \%$ (Tabela 2). 
Avanços e Recuos do Mercosul

Tabela 2 - Desempenho comercial do Mercosul, no período 1998 a 2007 (em US\$ Milhões)

\begin{tabular}{|c|c|c|c|c|c|c|c|c|c|c|}
\hline & 1998 & $\begin{array}{c}\text { Var. } \\
\%\end{array}$ & 1999 & $\begin{array}{c}\text { Var. } \\
\%\end{array}$ & 2000 & $\begin{array}{c}\text { Var. } \\
\%\end{array}$ & 2001 & $\begin{array}{c}\text { Var. } \\
\%\end{array}$ & 2002 & $\begin{array}{c}\text { Var. } \\
\%\end{array}$ \\
\hline $\begin{array}{l}\text { Comércio } \\
\text { intrazona } \\
\text { (A) }\end{array}$ & 40.814 & o & 30.584 & -25 & 35.276 & 15 & 30.545 & -13 & 20.462 & -33 \\
\hline $\begin{array}{l}\text { Comércio } \\
\text { extrazona } \\
\text { (B) }\end{array}$ & 135.829 & -2 & 122.922 & -10 & 135.944 & 11 & 138.965 & 2 & 128.132 & -8 \\
\hline $\begin{array}{l}\text { Comércio } \\
\text { total (C) }\end{array}$ & 176.644 & -2 & 153.505 & -13 & 171.220 & 12 & 169.510 & -1 & 148.594 & -12 \\
\hline \multirow[t]{2}{*}{$(\mathrm{A} / \mathrm{C})$} & \multicolumn{2}{|l|}{$23,1 \%$} & \multicolumn{2}{|l|}{$19,9 \%$} & \multicolumn{2}{|l|}{$20,6 \%$} & \multicolumn{2}{|l|}{$18,0 \%$} & \multicolumn{2}{|l|}{$13,8 \%$} \\
\hline & 2003 & $\begin{array}{c}\text { Var. } \\
\%\end{array}$ & 2004 & $\begin{array}{c}\text { Var. } \\
\%\end{array}$ & 2005 & $\begin{array}{c}\text { Var. } \\
\%\end{array}$ & 2006 & $\begin{array}{c}\text { Var. } \\
\%\end{array}$ & 2007 & $\begin{array}{c}\text { Var. } \\
\%\end{array}$ \\
\hline $\begin{array}{l}\text { Comércio } \\
\text { intrazona } \\
\text { (A) }\end{array}$ & 25.596 & 25 & 34.637 & 35 & 42.273 & 22 & 51.162 & 21 & 57.162 & 12 \\
\hline $\begin{array}{l}\text { Comércio } \\
\text { extrazona } \\
\text { (B) }\end{array}$ & $\begin{array}{c}146.64 \\
3\end{array}$ & 14 & 191.930 & 31 & 230.836 & 20 & 274.319 & 19 & 324.652 & 18 \\
\hline $\begin{array}{l}\text { Comércio } \\
\text { total }(\mathrm{C})\end{array}$ & $\begin{array}{c}172.23 \\
9\end{array}$ & 16 & 226.567 & 32 & 273.109 & 21 & 325.481 & 19 & 381.955 & 17 \\
\hline$(\mathrm{A} / \mathrm{C})$ & $14,9 \%$ & & $15,3 \%$ & & $15,5 \%$ & & $15,7 \%$ & & $15,0 \%$ & \\
\hline
\end{tabular}

FONTE: Elaboração própria com base em CEI (2008), citando INDEC, SECEX, Secretaria Administrativa do Mercosul, Banco Central do Uruguai e Banco Central do Paraguai.

Nota: Os valores de 2007 não incluem o Paraguai e o Uruguai. Cabe destacar a pequena participação desses países no comércio regional. Em 2006, eles representavam, somados, 12\% do comércio intrazona, 4\% do comércio extrazona e apenas $5 \%$ do comércio total dos quatro países do Mercosul.

No decorrer da terceira fase, o intercâmbio comercial do Mercosul, apesar de uma pequena recuperação no ano 2000, seguiu em forte declínio e, ao final do período, em 2002, o comércio intrabloco tinha sido reduzido à metade do que era em 1998. O índice de regionalização do comércio externo começou a despencar em 1999. Ele caiu de 23,1\% em 1998 para apenas 13,8\% em 2002, índice praticamente equivalente ao observado no início da formação do Mercosul (Tabela 2).

A desintegração comercial da região na terceira fase fica bem caracterizada no Gráfico 2: enquanto o intercâmbio comercial extrabloco permanecia estagnado entre 1999 e 2002, o intercâmbio dentro do bloco sofria acentuada retração. 


\section{Gráfico 2 - Intercâmbio comercial do Mercosul, no período 1998 a 2007} $(1991=$ base 100$)$

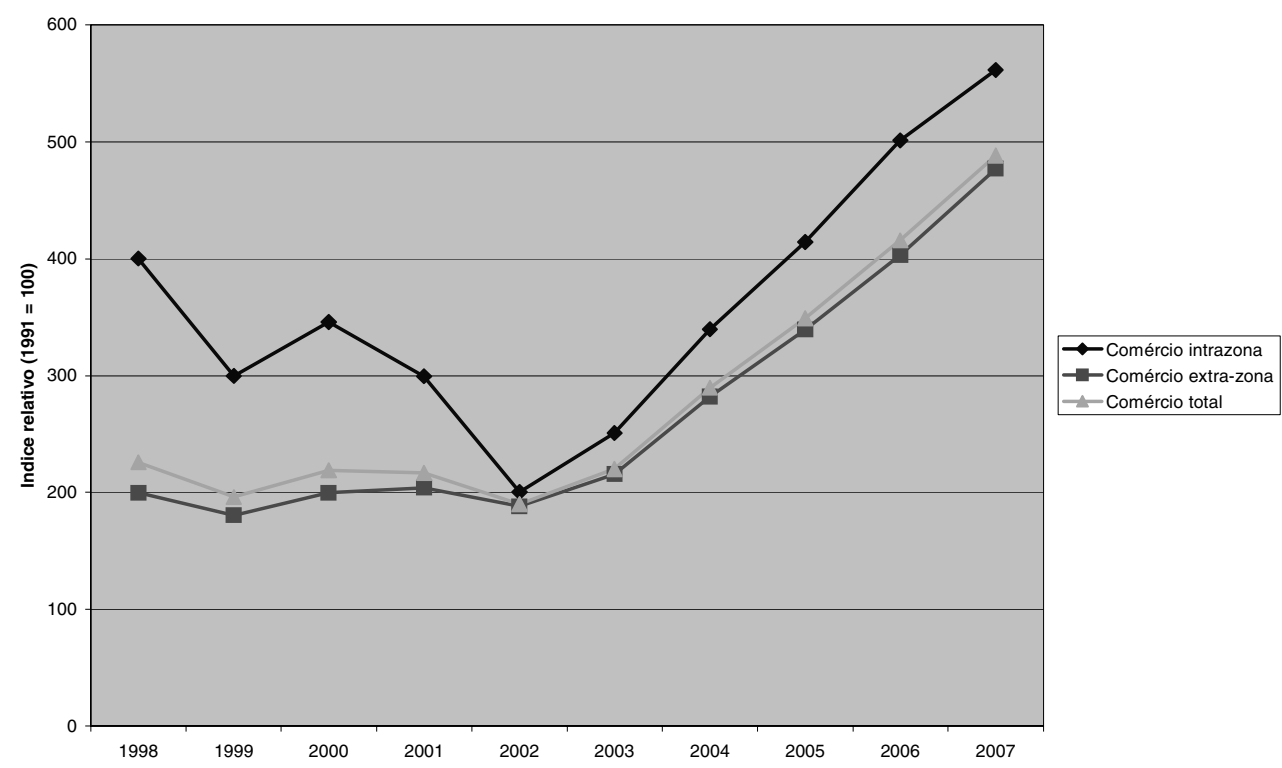

FONTE: Elaboração própria com base em CEI (2008), citando INDEC, SECEX, Secretaria Administrativa do Mercosul, Banco Central do Uruguai e Banco Central do Paraguai.

Contudo, verificou-se certo avanço na esfera da regulação comercial, visto que o tratamento tarifário especial para os produtos sensíveis, os quais seguiram o novo calendário automático de eliminação de tarifas, acordado no final de 1994 no âmbito do programa de liberalização comercial, encerrou-se, como havia sido planejado, em janeiro de 2000. Porém, este avanço não foi suficiente para ajudar a melhorar o desempenho comercial do bloco no decorrer do período analisado (1999 a 2002). Ademais, Bouzas (2001, p. 5) revela que os dois setores especiais (o açúcar e os veículos automotores) permaneceram fora do regime de liberdade comercial intrazona ${ }^{(8)}$.

No âmbito da agenda de relançamento do Mercosul, em outubro (2000), o Grupo de Monitoramento Macroeconômico (GMM) divulgou os indicadores econômicos relativos aos aspectos fiscais do bloco e, assim, antecipou os prazos previstos para a definição das metas macroeconômicas do Mercosul. Neste sentido, também, verificou-se um avanço, pois, em 15 de dezembro de 2000, os quatro sócios, a Bolívia e o Chile assinaram a Declaração Presidencial sobre Convergência Macroeconômica e, com isto, formalizaram as metas e os mecanismos de convergência macroeconômica do bloco.

Com relação à TEC verificou-se retrocesso, pois, segundo Almeida (2002, p. 8), em março de 2001, em atmosfera de crise, o ministro da economia da Argentina, Domingo

(8) O autor detalha que "O açúcar deveria ter sido incluído nas regras gerais em dezembro de 2000, mas os países membros não conseguiram alcançar um acordo. A questão permanece pendente, ainda hoje (2001). Um regime comum para veículos automotores foi finalmente acordado em março de 2000”. (BOUZAS, 2001, p. 5) 
Cavallo, suspendeu unilateralmente a vigência da TEC para dois grupos de importações (bens de consumo corrente e bens de capital). E os países-membros, a fim de não agravar a situação de crise política enfrentada pelo bloco desde a desvalorização do real, ratificaram, em abril de 2001, as referidas "exceções temporárias" acordadas com a Argentina.

Assim, de acordo com Beçak (2000, p. 19), quanto mais os países envolvidos em um esquema de integração regional se aproximam da integração profunda maiores são as dificuldades enfrentadas por eles, devido às concessões e à harmonização que devem ser promovidas.

Ademais, agrega-se nesta questão o fato de que, logo no início do período (meados de 1998 e início de 1999), instalou-se na região uma forte crise financeira, a qual acometeu individualmente cada um dos países-membros, assim como a maioria dos mercados emergentes do globo. Neste sentido, o balanço do período apresenta, no geral, um saldo negativo, visto que os avanços foram muito modestos e os países-membros, devido ao conturbado contexto macroeconômico, estabeleceram prioridades individuais acima das prioridades comuns aos membros do bloco. A síntese desse saldo negativo foi a desintegração comercial do Mercosul no período, refletida pela forte diminuição do índice de regionalização do comércio externo.

\section{A QUARTA FASE: 2003 A 2007}

No ano de 2003, o desempenho comercial do bloco melhorou substancialmente. O intercâmbio entre os países do Mercosul e o comércio total com o resto do mundo cresceram, em relação a 2002, 25\% e 14\%, respectivamente (Tabela 2).

Ademais, no período compreendido entre 2003 e 2007, o intercâmbio comercial do bloco apresentou bons resultados, visto que, a partir de 2003, o indicador sempre apresentou variações positivas, indicando que, em relação à fase anterior (1999 a 2002), as relações comerciais do mercado regional, no geral, melhoraram significativamente (Gráfico 2). Depois de sofrer forte contratação em 2002, como já foi observado, o índice de regionalização do comércio externo voltou a crescer no período de 2003 a 2007 (passou de 13,8\% para cerca de $15 \%$ ), ainda que de forma modesta e sem repetir o bom desempenho do período de 1995 a 1998 (Tabela 1 e Tabela 2). De qualquer forma, o comércio intrabloco cresceu entre 2003 e 2007 cerca de $123 \%$. Foi um crescimento bastante expressivo. Por outro lado, o crescimento do comércio extrazona foi similar (121\%), o que sugere que o aumento do comércio dentro do bloco tenha sido influenciado de forma preponderante por uma melhora geral do comércio externo da região.

O período que se iniciou no primeiro semestre de 2003 abriu, segundo INTAL (2004, p. 65), "uma janela de oportunidade para a agenda interna do Mercosul”. A convergência das políticas cambiais, a retomada do crescimento econômico na região e a posse de presidentes claramente favoráveis ao Mercosul deram origem a um clima propício aos entendimentos entre os países-membros.

Reforçando a ideia da existência de um clima propício ao bloco, Sica (2006, p. 7-9) destaca que 
los países atraviesan un nuevo período de crecimiento económico y comercial, aunque matizado por los insistentes reclamos de parte de los países más perjudicados y el surgimiento de conflictos sectoriales intrabloque. (...) todos los países crecen, y muestran saludables indicadores económicos que permiten inferir que la actual etapa de expansión no será efímera.

No decorrer dos anos 2003 e 2004, a maioria dos temas da agenda interna avançou. No entanto, alguns temas lograram maior êxito do que outros. Por exemplo, verifica-se que, no âmbito da coordenação das políticas macroeconômicas, o processo progrediu, pois as políticas cambiais dos países-membros passaram a convergir. Ademais, o GMM propôs uma metodologia comum para o cálculo do núcleo de inflação, além de iniciar discussão relativa à possibilidade de se harmonizar os agregados monetários no Mercosul.

No que concerne à TEC, INTAL (2004, p. 66) revela que o avanço foi tímido, pois os países-partícipes conservam as exceções à TEC por meio de sucessivas prorrogações nas datas originalmente previstas para a suspensão das mesmas.

Entretanto, a constituição do FOCEM, em 2005, criado com o propósito de desenvolver ações destinadas a promover a competitividade e a convergência estrutural dos países-membros, e a fundação do Banco do Sul, em 9 de dezembro de 2007, cuja finalidade é financiar projetos de desenvolvimento na região e ser uma alternativa às instituições financeiras multilaterais existentes, são exemplos dos logros verificados no âmbito institucional, no período analisado (2003 a 2007).

Portanto, ao compararmos os acontecimentos da quarta fase (2003 a 2007) com os fatos transcorridos na fase anterior (1999 a 2002), o balanço do período atual apresentaria, no geral, um saldo positivo. A volta do crescimento do comércio intrabloco e a retomada da agenda interna, e os seus logros no âmbito institucional, constituem avanço no processo de consolidação e aprofundamento do projeto de integração do Cone Sul. No entanto, as negociações entre o Uruguai e os Estados Unidos da América para um acordo de preferências comerciais bilaterais, o conflito entre o Uruguai e a Argentina com relação à construção de duas plantas de celulose na fronteira destes países e a decisão do governo boliviano que nacionalizou os ativos da empresa Petróleo Brasileiro S.A, nos mostram que, na verdade, o balanço do período, ainda que positivo, revela que o processo de integração regional segue tendo desafios a superar.

\section{Conclusões}

O início da aproximação entre os países do Cone Sul se deu na segunda metade da década de 70, porém, foi em meados dos anos 80 , quando as iniciativas regionais de organizações em blocos de países ganharam forte impulso no mundo (Europa, Estados Unidos e Ásia), que o Brasil e a Argentina, estimulados pelo novo contexto mundial e com base no conceito de regionalismo aberto, difundido pela CEPAL, iniciaram sua integração econômica, primeiramente, com a instituição do PICE, em 1986, e, posteriormente, com a assinatura do Tratado de Integração, Cooperação e Desenvolvimento, em 1988. Após outros acordos e uma boa repercussão regional, em março de 1991, os presidentes da Argentina, 
do Brasil, do Paraguai e do Uruguai constituíram, por meio da assinatura do Tratado de Assunção, o Mercosul.

O Tratado de Assunção instituiu os instrumentos e objetivos da integração econômica, contudo, o propósito maior do tratado era estabelecer, até 31 de dezembro de 1994, o Mercado Comum do Sul.

É possível identificar na trajetória do Mercosul quatro fases distintas, sendo que duas ocorreram ao longo de sua primeira década (1991 a 1998) e duas durante o período recente (1999 a 2007). O presente artigo buscou relacionar as características destes quatro períodos com acontecimentos que indicassem o alcance, ou não, dos objetivos estabelecidos no Tratado de Assunção e mais adiante, no decorrer do próprio processo de integração, para, deste modo, responder em que medida o Mercosul está ou não enfrentando uma nova crise.

Na primeira fase, de 1991 a 1994, os quatro países avançaram significativamente no campo da liberalização do comércio intrarregional, pois, ao final do período, a maior parte dos produtos comercializados entre os países-membros circulava com isenção de impostos. Portanto, apesar de não ter sido alcançado, no prazo, o maior objetivo do Tratado de Assunção (o mercado comum), o período apresentou avanços para a consolidação do bloco, visto que os fluxos de comércio intrarregionais se intensificaram substancialmente.

Já a segunda fase, de 1995 a 1998, foi marcada por muitos impasses e temas pendentes, pois a agenda de negociação se tornou mais complexa e conflitiva. Entretanto, o aumento da interdependência comercial, registrado até meados de 1998, e a implementação da TEC, mesmo que com uma série de exceções, foram os maiores avanços do período. $\mathrm{Na}$ segunda fase, a regionalização do comércio internacional seguiu crescendo e atingiu seu máximo, indicando ascendente integração comercial entre os países-membros.

Na terceira fase, de 1999 a 2002, deflagrou-se na região um cenário comum de incerteza e recessão econômica, causada pelo conturbado contexto macroeconômico internacional. Diante desse contexto e visto que quanto mais se avança em direção à integração profunda maiores são as dificuldades enfrentadas pelos países envolvidos, o balanço do período apresentou um saldo negativo, pois os países-membros estabeleceram prioridades individuais em detrimento das prioridades comuns aos membros do bloco. Houve forte redução do comércio intrabloco, com diminuição significativa da regionalização do comércio externo. Foi uma fase de crise para o Mercosul.

A quarta fase, de 2003 a 2007, é marcada pela retomada do crescimento econômico na região, pela posse de chefes de estado favoráveis ao Mercosul, por uma recuperação da "esquecida" agenda interna do bloco e por uma significativa melhora nos fluxos de comércio intra e extrazona. No entanto, o período apresentou um saldo que revela dificuldades para o bloco, pois, apesar dos avanços verificados na esfera comercial e institucional, ocorreram muitos conflitos, os quais refletem que os sócios têm uma grande dificuldade para redefinir os rumos do seu esquema de integração.

No decorrer de sua trajetória o Bloco logrou avanços significativos, principalmente na esfera comercial, pois comparando-se o resultado do ano de 2007 com o início do processo 
de integração (1991), se verifica um crescimento do comércio intrabloco de $460 \%{ }^{(9)}$. Ademais, verificamos que, após um período de estagnação (1999 a 2002), ocorreu uma retomada da agenda interna do bloco, a qual revela que os sócios seguem na tentativa de consolidar e aprofundar o esquema de integração da região. Portanto, os conflitos transcorridos nos últimos anos não refletem uma crise do esquema de integração da região sul-americana, pelo contrário, revelam uma possível intensificação do processo de integração. Neste sentido, seria interessante analisar o papel do Brasil como peça-chave para superar estes conflitos e, assim, propiciar um efetivo aprofundamento do esquema de integração da região, visto que o bloco mantém sua condição de "união aduaneira imperfeita" até os dias de hoje.

\section{REFERÊNCIAS BibLIOGRÁfiCAS}

ALMEIDA, Paulo R. de. Mercosul em sua primeira década (1991-2001): uma avaliação política a partir do Brasil. Buenos Aires: INTAL-ITD-STA, 2002.

Mercosul: fundamentos e perspectivas. São Paulo: LTr, 1998.

APPLEYARD, Dennis R.; FIELD JR., Alfred J. International economics. 4. ed. Boston: McGraw Hill, 2001.

AVERBUG, André. Mercosul: conjuntura e perspectivas. Revista do BNDES, Rio de Janeiro, v. 5, n. 10, 1998. Disponível em: <http://www.bndespar.com.br/conhecimento/revista/rev1006.pdf> Acesso em: 9.7.2006.

BALASSA, Bela. Teoria da integração econômica. 2. ed. Lisboa: LCE, 1972.

BEÇAK, Peggy. Mercosul: uma experiência de integração regional. São Paulo: Contexto, 2000.

BOUZAS, Roberto. As perspectivas do Mercosul: desafios, cenários e alternativas para a próxima década. In: CAMPBELL, Jorge (org.). Mercosul: entre a realidade e a utopia. Rio de Janeiro: Relume Dumará, 2000.

. Mercosul, dez anos depois: processo de aprendizado ou déjà-vu? Rio de Janeiro: FUNCEX, 2001. Disponível em: <http://www.funcex.com.br/bases/68-Integra\%E7ao-RB.pdf> Acesso em: 4.3.2007.

BRANDI, Juan Pedro. Mercosur: entre el tratamiento de las "asimetrías" y el debate comercial. Revista del CEI, Buenos Aires, n. 10, p. 19-30, dez. 2007. Disponível em: <http://cei.mrecic.gov.ar/ revista/10/parte\%202.pdf> Acesso em: 1ํ‥3.2008.

BRASIL. Ministério das Relações Exteriores. Ata Oficial - XIX Reunião do Conselho do Mercado Comum. Disponível em: <http://www2.mre.gov.br/xixmercosulTextos/ata.htm> Acesso em: 26.8.2007.

CONSTÂNCIO, Tânia. Efeitos dinâmicos da integração de Portugal na UE. Coimbra: CEUNEUROP, 2005.

CEI. Centro de Economía Internacional. Estadísticas Mercosur. Disponível em: <http://cei. mrecic.gov.ar/html/mercosur.htm> Acesso em: 29.5.2008.

(9) A expansão do comércio intrabloco foi maior do que a verificada no comércio extrabloco. O comércio extrabloco cresceu no período analisado $377 \%$. Embora tenha sido um crescimento menor que o comércio intrabloco, a expansão do comércio com países de outras regiões foi expressivo, o que sugere que a expansão simultânea dos dois tipos de comércio é possível. 
INTAL. Instituto para a Integração da América Latina e do Caribe. Informe Mercosul 6. Buenos Aires: BID-INTAL, 2000.

Informe Mercosul 9. Buenos Aires: BID-INTAL, 2004.

MACHADO, João Bosco M. Mercosul: processo de integração: origem, evolução e crise. São Paulo: Aduaneiras, 2000.

MINISTÉRIO DAS RELAÇÕES EXTERIORES. Mercosul no governo do presidente Lula. Disponível em: <http://www.mre.gov.br/portugues/politica_externa/mercosul/mercosul/mercosul _lu006Ca.asp> Acesso em: 26.8.2007.

MUARREK, Itiberê. Globalização e as perspectivas do Mercosul: uma análise político-econômica. São Paulo, 2004. 171 f. Dissertação (Mestrado em Economia) - Pontifícia Universidade Católica de São Paulo - PUC/SP, 2004.

PEREIRA, Lia Valls. Tratado de Assunção: resultados e perspectivas. In: BRANDÃO, Antônio Salazar P.; PEREIRA, Lia Valls. Mercosul: perspectivas da integração. 3. ed. Rio de Janeiro: FGV, 1998.

PORTAL OFICIAL DO MERCOSUL. Protocolo de Olivos para a Solução de Controvérsias no Mercosul. 2002. Disponível em: <http://www.mercosur.int/msweb/portal\%20intermediario/pt/ index.htm > Acesso em: 20.5.2007.

PORTAL OFICIAL DO MERCOSUL. Quem somos. Disponível em: <http://www.mercosur.int/ msweb/portal\%20intermediario/pt/index.htm> Acesso em: 20.5.2007.

SALVATORE, Dominick. Economia internacional. 6. ed. Rio de Janeiro: LTC, 2000.

SICA, Daniel. Mercosur: evolución y perspectivas. Puerto Madero: Abeceb.com, 2006. Disponível em: <http://www.memorial.sp.gov.br/images/noticia/o00590/Sica_Informe_Seminario_Memo rial_Final.pdf> Acesso em: 5.8.2007. 